\title{
An Occult Case of Worsening Dyspnoea in Adult Affected by Anatomic Abnormalities of Oral Cavity: A Case Report
}

\author{
Pierluigi Gucciardino*, Saverio Paventi and Mario Bosco \\ Santo Spirito Hospital of Rome, Italy
}

Received: 鮆 January 11, 2018; Published: 眥 January 18, 2019

*Corresponding author: Pierluigi Gucciardino, Santo Spirito Hospital of Rome, Borgo Santo Spirito 300193 Rome, Italy

\section{Introduction}

Aspiration of foreign bodies (FBs) occurs frequently in children and most of all occurs in children of about three years old [1]. However, FB aspiration can occur in adults and elderly people [2] but the real incidence is not known. The nature of foreign bodies aspiration in adult population is usually related to eating habits and the clinical presentation depends on the site of FB impaction. Bronchial aspiration usually presents as an acute event, but sometimes it may manifest itself insidiously making diagnosis very difficult. Since the improvement of both rigid and flexible bronchoscopes, the survival is good and morbidity is low [3]. Here we report a case of patient affected by tongue cancer who inhaled a $6 \mathrm{~cm}$ foreign alimental body and was admitted to the emergency department two day after the aspiration presenting non-specific symptoms.

\section{Case Presentation}

A 65-old Italian man was admitted at 4 pm to the emergency department presenting worsening dyspnoea developed two days before during the normal daily activities. Significant alcoholism and tobacco smoking story was noted. The past medical history consisted of anxiety and depression, epidermoid tongue cancer treated by pull through operation, extended right cervical lymphadenectomy and temporary tracheotomy in 2011 (pT1N0G3), chronic cerebral vasculopathy and pace-maker implantation for trifascicular block. General examination revealed a mild cooperative and pale male. The oral cavity presented the surgical sign of previous partial tongue resection and neck examination showed the signs of previous tracheotomy (Figure 1). Respiratory examination revealed patient affected by dyspnoea and reduction of breath sounds in the left hemithorax. Cardiovascular auscultation revealed arrhythmic heart sounds. Abdominal examination was unremarkable. The patient presented altered vital signs: artery pressure of 140/80 mmHg; arrhythmic pulse of $112 \mathrm{bpm}$; arterial oxygen saturation of of $74 \%$ a/a. He was not febrile. Abnormal laboratory investigations included: white blood cells $17.1 \mathrm{x} 103 / \mathrm{uL}$ (4.00-10.00); D-Dimer $352 \mathrm{ng} / \mathrm{ml}$ (< 278); Glycemia $197 \mathrm{mg} / \mathrm{dl}$ (70-110); NT-pro BNP $2741 \mathrm{ng} / \mathrm{L}(<450)$; cardiac T troponin $21.12 \mathrm{ng} / \mathrm{L}(0-14)$; reactive C protein (RCP) $94.1 \mathrm{mg} / \mathrm{L}$ (0-5). Electrocardiogram showed atrial fibrillation. Chest X-ray (CXR) was performed in supine position and demonstrated complete opacification of the left hemithorax with shift of cardiac structures to the left side, hyperexpansion of the right lung, no estimable cardiac imaging, no pleural effusion on the right, pace-maker device on the left side (Figure 2). The arterial blood gas analysis showed: pH 7.52; PaCO2 24.1 mmHg; PaO2 34.6 $\mathrm{mmHg}$; arterial oxygen saturation of $73.9 \%$; lactates $3.1 \mathrm{mmol} / \mathrm{L}$; HCO3- 20.1 mmol/L; BEecf -3.0 mmol/L; PaO2/FiO2 165.7 mmHg. Antibiotic prophylaxis (Ceftriaxone $1 \mathrm{~g}$ and Metronidazole 1500 $\mathrm{mg}$ ) and oxygen therapy (FiO2 1) were given.

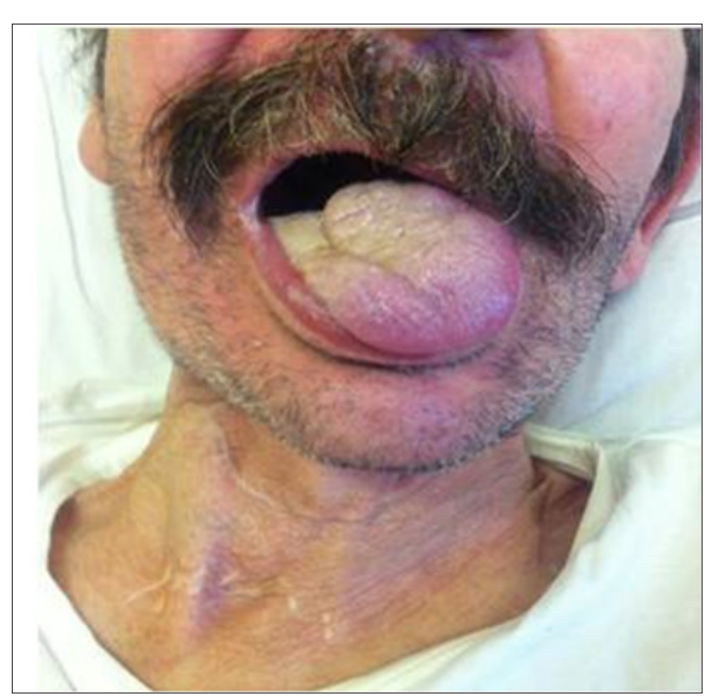

Figure 1: Patient's oral cavity. 


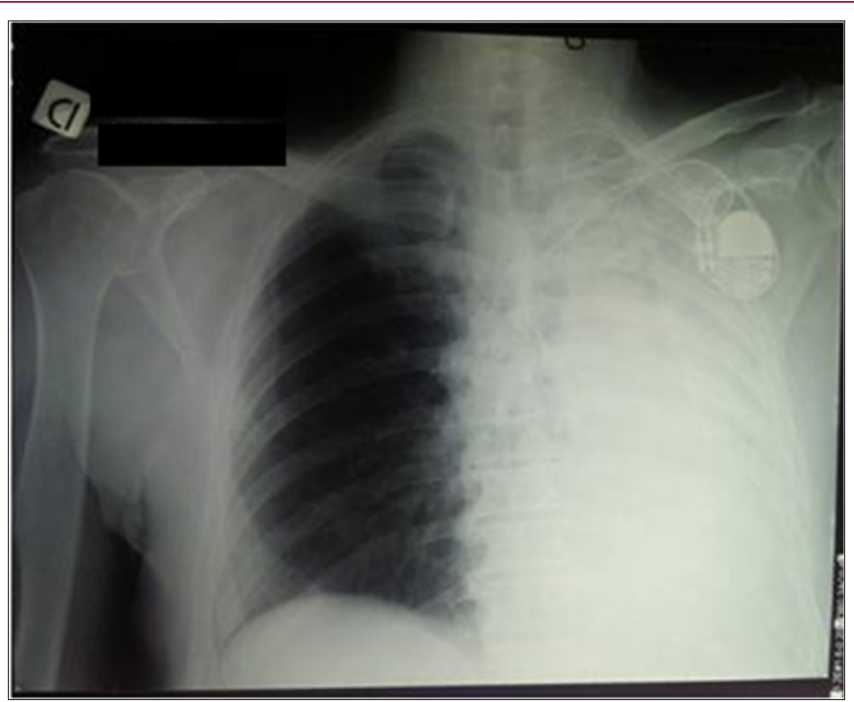

Figure 2: Admission chest X-ray.

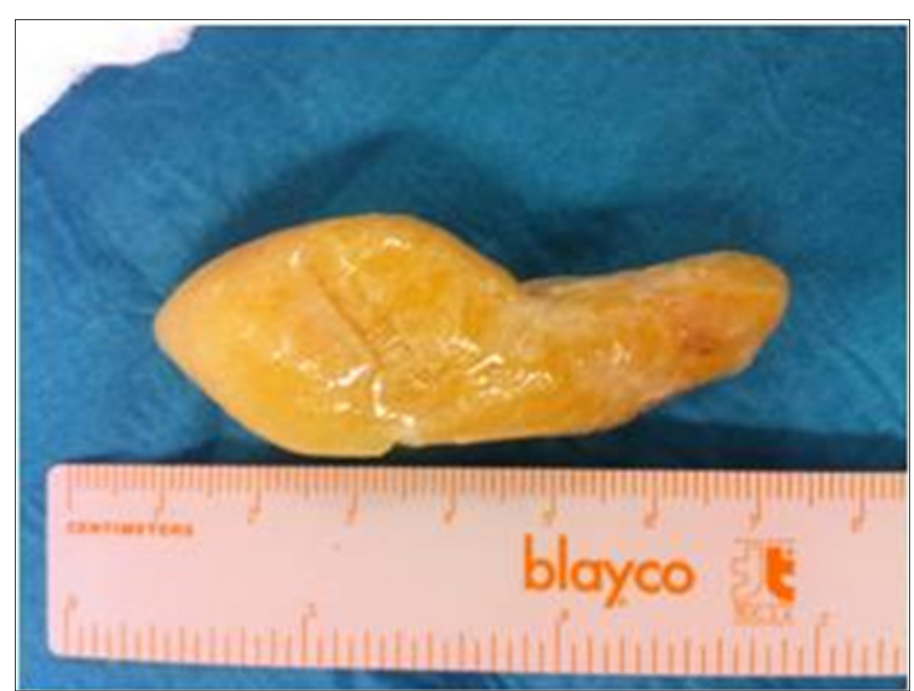

Figure 3: The foreign body removed.

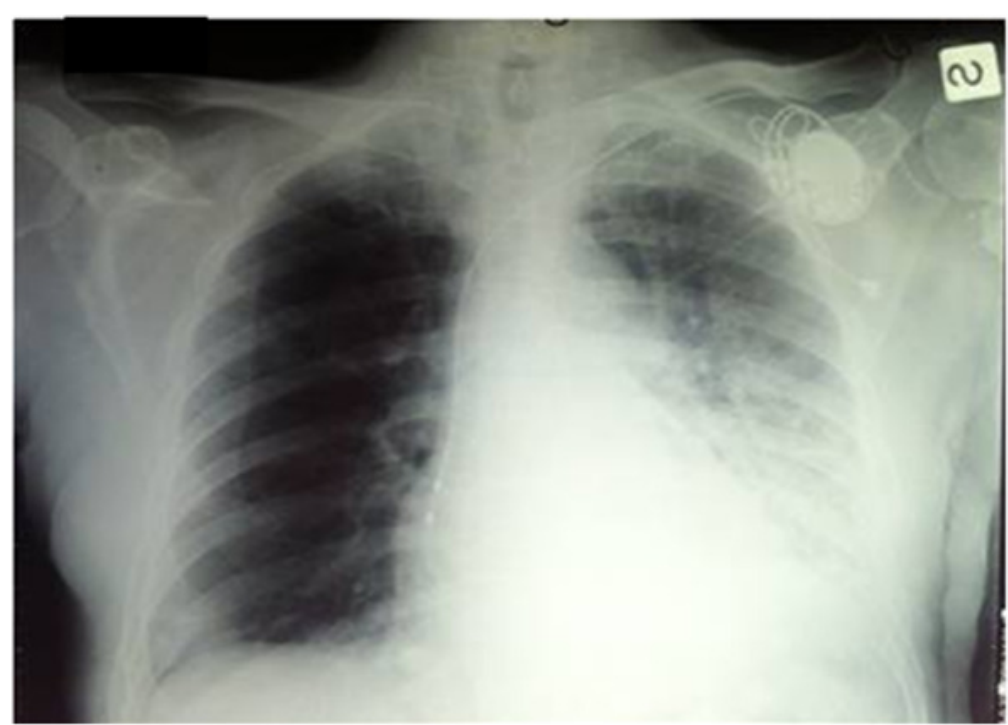

Figure 4: Chest $X$-ray 30 minutes after operating bronchoscopy. 
Immediately, the patient presented arterial oxygen saturation of $90 \%$ and stable vital signs. Preliminary flexible fibreoptic bronchoscopy was performed at $5 \mathrm{pm}$. Procedure was performed after that Lidocaine $1 \%$ was used as a topic anesthetic and sedation was induced. The preliminary fibreoptic bronchoscopy revealed a foreign body that occluded the left main bronchus. Subsequently, an operating bronchoscopy was performed and the foreign body was removed easily because during the procedure, a fit of coughing pushed the foreign body to the higher respiratory airways. The foreign body removed was a $6 \mathrm{~cm}$ dry apricot that patient did not refer to have eaten at the moment of the admission (Figure 3). After the operating bronchoscope, patient presented a slow resolution of dyspnea. A second CXR was performed 30 minutes after the endoscopic procedure (Figure 4). The mediastinal structures were aligned, partial clarification of the respiratory field and clear reduction of massive atelectasis were evident. The arterial blood gas analysis showed: $\mathrm{pH} 7.51 ; \mathrm{PaCO}_{2} 26.3 \mathrm{mmHg} ; \mathrm{PaO}_{2} 70.0 \mathrm{mmHg}$; arterial oxygen saturation of 95.5\%; lactates $1.0 \mathrm{mmol} / \mathrm{L}$; HCO321.4 mmol/L; BEecf -1.8 mmol/L; PaO2/Fi02 334.6 mmHg. Patient was then admitted to the pulmonology ward. Antibiotic prophylaxis was prolonged during the hospitalization (Ceftriaxone $1 \mathrm{~g} / \mathrm{die}$; Fluoroquinolone $500 \mathrm{mg} /$ die and Metronidazole $1500 \mathrm{mg} / \mathrm{die}$ ).

Oxygen therapy associated to aerosol therapy (Fluticasone and Ipratropio/Salmeterol) were performed. We performed daily respiratory function tests and controls of inflammatory markers (Figure 5). Six days after the admission, he underwent chest high resolution computed tomography (HRCT) scan that showed diffused interstitial and bronchial wall thickness; quiet pleural effusion stratum on the left side; interstitial and alveolar extended inflammatory/infective impairment. He presented slow improvement of $\mathrm{PO}_{2}$ and saturation values. Finally, the patient was discharged in good clinical conditions 20 days after primary admission.

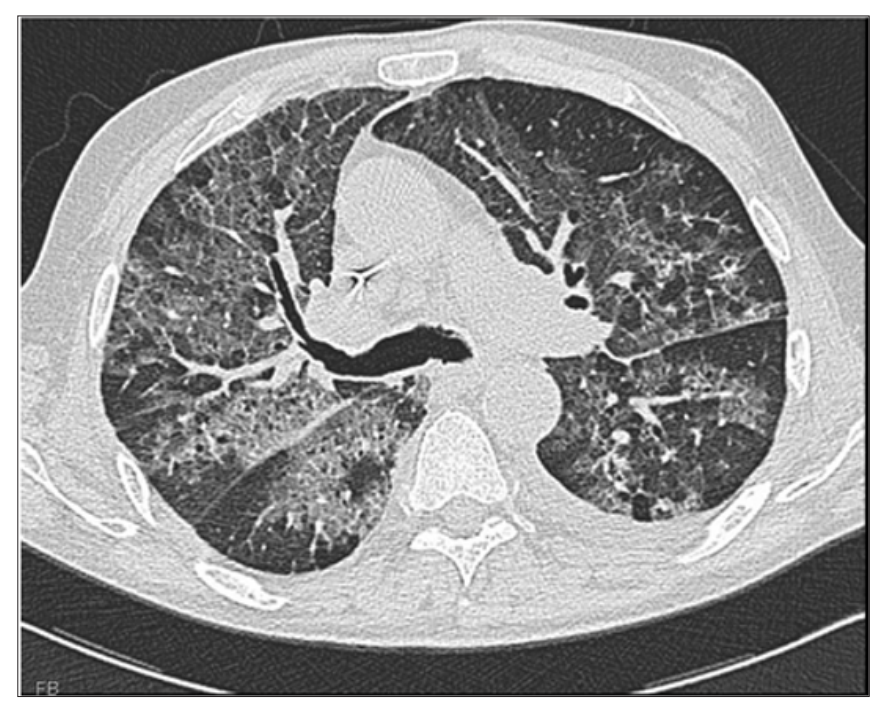

Figure 5: Chest HRCT scan 6 days after foreign body removal.

\section{Discussion}

Aspirated foreign bodies (FBs) continues to present challenges to doctors. The nature and spectrum of aspirated FBs differ according to age, sex, life style, and eating habits. It is more common in children who explore the world by introducing the objects in their mouths and do not have premolars or molars to grind smaller inhalable pieces [4]. Furthermore, they have an immature protective cough reflex, compared to adults. Young children usually inhale object like toys or other household items. On the contrary, bronchoaspiration of foreign body in adult is not common but in case of abuse of sedative medications, alcohol consumption, neurological disorders (vascular dementia, Parkinson's), poor dentition and/or mental retardation, it could be frequent [5-7]. Elderly people usually inhale organic material. Common early signs and symptoms of aspiration may include dyspnoea, coughing, inspiratory stridor, cyanosis and decreased oxygen saturation, but they may manifest themselves insidiously.

Often, adults do not spontaneously report the episode of choking and the finding of the FB may be fortuitous when bronchoscopy is performed because of chronic symptoms such as cough, hemoptysis and repeated or prolonged pneumonia [8]. Non-specific symptoms can delay the diagnosis increasing patient's risk of important complications. In fact, FBs represents a medical emergency in all ages with serious and potentially lethal consequences such as vocal cord paralysis, abscess, infection, pneumothorax that sometimes can lead to loss lung tissue and to death [9-10]. Our patient presented vague symptoms and did not spontaneously report significant anamnestic information probably because he did not realize to have inhaled a foreign body. He was admitted to our emergency department two day after the aspiration. The patient presented significant story of alcoholism and he presented anatomic abnormalities of oral cavity conditioning chewing due to the previous tongue operation.

Probably, these conditions influenced his capacity to swallow. The foreign body can impact at any site from the laryngeal inlet to the terminal bronchioles. Its location is strictly correlated with patients' age. In fact, the main stem bronchi diverge from the trachea with different angles increasing age. According to this 
divergence, the right main stem bronchus aligns with the trachea making a relatively continuity from the larynx to the right bronchus. Therefore, the inhaled objects are more commonly found in the right than the left side of the bronchial tree [11-13]. Accordingly, chest radiography should be performed every time in suspect of foreign body aspiration because more than $90 \%$ of foreign bodies are radiolucent. Before the introduction of modern respiratory endoscopy techniques, the mortality rate due to aspiration of FBs aspiration was around 24\% [14]. Currently, bronchoscopy should be performed in all cases of suspected FB aspiration, even if the radiological findings are normal [15-16].

Flexible brochoscopy is considered the gold standard in diagnosis and treatment of FBs although serious complications, such as mediastinal emphysema, atelectasis, pneumothorax, and tracheoesophageal fistula, have been reported after bronchoscopy [17-18]. Therefore, patients should be initially submitted to flexible bronchoscopy to locate the foreign body in the tracheobronchial tree, evaluate the degree of inflammation or suppuration of the bronchial mucosa, and choose the equipment that was necessary for therapeutic measures and then underwent therapeutic bronchoscopy. Surgical treatment should be reserved for cases in which bronchoscopy is unsuccessful or there are irreversible bronchial or lung complications.

\section{Conclusion}

Broncho aspiration of foreign body in adult is not common. It could be frequent in some group of patients such as people affected by abuse of sedative medications, alcohol consumption, neurological disorders, poor dentition and/or mental retardation. Anatomic abnormalities of oral cavity can condition the swallow process increasing the probability of foreign body aspiration. Clinical presentation can manifest itself insidiously and the diagnosis can be delayed amplifying patient's risk of important complications. Currently, preliminary and operating fibreoptic bronchoscopy are considered the gold standard to treat patients affected by foreign body aspiration. Endoscopic procedure should be performed in all cases of suspected foreign body aspiration.

\section{References}

1. Hui H, Na L, Zhijun CJ, Fuagao ZG, Yan S, et al. (2008) Therapeutic experience from 1428 patients with pediatric tracheobronchial foreign body. J Pediatr Surg 43(4): 718-721.

2. Lameze R, Trechot P, Martinet Y (1994) Bronchial necrosis and granuloma induced by the aspiration of a tablet of ferrous sulphate. Eur Respir J 7: 1710-1711.
3. Mehta AC, Rafanan AL (2001) Extraction of airway foreign body in adults. J Bronchol 8(2): 123-131.

4. Cohen S, Avital A, Godfrey S, Gross M, Kerem E, et al. (2009) Suspected foreign body inhalation in children: what are the indications for bronchoscopy? J Pediatr 155(2): 276-280.

5. Irwin RS, Ashba JK, Braman SS, Lee HY, Corrao WM (1997) Food asphyxiation in hospitalized patients. JAMA 237(25): 2744-2745.

6. Rahulan V, Patel M, Sy E, Menon L (2003) Foreign body aspiration in elderly: an occult cause of chronic pulmonary symptoms and persistent infiltrates. Clin Geriatr 11: 41-43.

7. Fields RT Jr, Schow SR (1998) Aspiration and ingestion of foreign bodies in oral and maxillofacial surgery: a review of the literature and report of five cases. J Oral Maxillofac Surg 56(9): 1091-1098.

8. Ramos MB, Fernández Villar A, Rivo JE, Leiro V, García Fontán E, et al. (2009) Extraction of airway foreign bodies in adults: experience from 1987-2008. Interact Cardiovasc Thorac Surg 9(3): 402-405.

9. Adelman HC (1988) Asphyxial deaths as a result of aspiration of dental appliances: A report of three cases. J Forensic Sci 33(2): 389-395.

10. Davies H, Gordon I, Matthew DJ, Helms P, Kenney IJ, et al. (1990) Long term follow up after inhalation of foreign bodies. Arch Dis Child 65(6): 619-621.

11. Karakoc F, Karadog B, Akbenlioglu C, Ersu R, Yildizeli B, et al. (2002) Foreign body aspiration: what is the outcome? Pediatr Pulmonol 34(1): 30-36.

12. Hasdiraz L, Bicer C, Bilgin M, Oquzkaya F (2006) Turban pin aspiration: non asphyxiating tracheobronchial foreign body in young Islamic women. Thorac Cardiov Surg 54(4): 273-275.

13. Asif M, Ali Shah S, Khan F, Ghani R (2007) Foreign body inhalation site of impaction and frequency of rigid bronchoscopy. J Ayub Med Coll Abbottabad 19(2): 46-48.

14. Kramer TA, Riding KH, Salkeld LJ (1986) Tracheobronchial and esophageal foreign bodies in the pediatric population. J Otolaryngol 15(6): 355-358.

15. Orji FT, Akpeh JO (2010) Tracheobronchial foreign body aspiration in children: how reliable are clinical and radiological signs in the diagnosis? Clin Otolaryngol 35(6): 479-485.

16. Korlacki W, Korecka K, Dzielicki J (2011) Foreign body aspiration in children: diagnostic and therapeutic role of bronchoscopy. Pediatr Surg Int 27(8): 833-837.

17. Kaptanoglu M, Nadir A, Dogan K, Sahin E (2007) The heterodox nature of Turban Pins in foreign body aspiration; the central Anatolian experience. Inter J Pediatr Otorhinolaryngol 71(4): 553-558.

18. Wong KS, Lai SH, Lien R, Hasia SH (2002) Retrieval of bronchial foreign body with central lumen using a flexible bronchoscope. Int J Pediatr Otorhinolaryngol 62(3): 253-256. 


\section{ISSN: 2574-1241}

DOI: 10.26717/BJSTR.2019.13.002387

Pierluigi Gucciardino. Biomed J Sci \& Tech Res

(C) (P) This work is licensed under Creative

Submission Link: https://biomedres.us/submit-manuscript.php

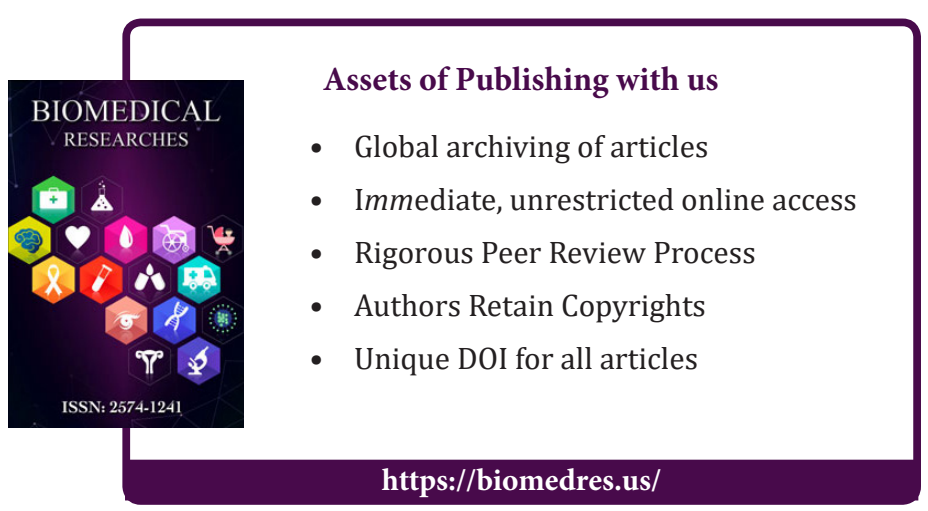

